CATALANO, J, F., \& WHALEN, P. M. The effects of auditory stimulation on pursuit rotor performance. Perceptual \& Motor Skills, $1967 \mathrm{~b}, 25,981-988$.

CROWNE, D, P., \& MARLOWE, D. A new scale of social desirability independent of psychopathology. Journal of Consulting Psychology, 1960, 24, 349-354.
EDWARDS, A. L. Edwards Personal Preference Schedule. New York: Psychological Corporation, 1954.

HULL, C. L. Principles of behavior. New York: Appleton-Century-Crofts, 1943.

STRICKLAND, B. R., \& JENKINS, O. Simple motor performance under positive and negative approval motivation. Perceptual \& Motor Skills, 1964, 19, 599-605.

\title{
Intra-group similarity and the rejection of a deviate ${ }^{1}$
}

JA Y HEWITT and DAVID MCLAUGHLIN, University of Victoria, Victoria, B.C., Canada

Each $S$ was informed that she was part of a five-person group, three of whose members agreed with her on a certain issue (the fellow members of the majority) and one of whom disagreed with her the deviate). In a 2 by 2 factorial design, Ss were lead to believe that they were either similar or dissimilar in personality to the other members of the majority and were either similar or dissimilar to the deviate. The Ss were given an opportunity to communicate with the deviate who refused to alter her initial position. The Ss broke off communication with the deviate sooner when there was a high similarity between themselves and the deviate than when there was a low similarity.

It seems logical to predict that the greater the similarity, attraction, or cohesiveness among the members of a group, the more time and effort will the group expend in attempting to modify the behavior of a deviate. Festinger's theory of informal social communication (Festinger, 1950) makes just the opposite prediction. Although high cohesive groups should initially expend greater effort in attempting to modify the behavior of a deviate, Festinger's theory predicts that if the deviate continues to violate the norms of the group, cohesiveness will be directly related to the speed with which the deviate will be rejected. The latter hypothesis has received some support when rejection is defined as a negative attitude toward the deviate. In experiments by Schachter (1951) and Emerson (1954), groups of Ss were asked to discuss a certain issue. A high degree of cohesiveness was induced in half of the groups, a low degree of cohesiveness in the remaining groups. A confederate (the deviate) was placed in each group and instructed to take a stand that was discrepant from the majority opinion. In both studies, the deviate was seen as a less desirable group member when group cohesiveness was high than when it was low.

The purpose of the present experiment was to extend the generality of these findings. In the Schachter (1951) and Emerson (1954) studies, rejection was defined as a negative attitude toward the deviate. In the present experiment, rejection was defined as the cessation of interaction with the deviate. In order to provide a more rigorous test of Festinger's hypothesis, however, several important aspects of the Schachter and Emerson procedure had to be modified. First, the Ss were allowed to communicate only with the deviate. In the Schachter (1951) and Emerson (1954) studies, Ss could communicate with anyone in the group. If Ss are allowed to communicate with anyone in the group, members of high cohesive groups might well direct fewer communications to the deviate during the final stages of communication than would their counterparts in low cohesive groups. This finding could be explained by assuming that the members of high cohesive groups had a greater desire to reject the deviate or by assuming that the members of high cohesive groups had a greater desire to communicate with one another. If Ss are allowed to communicate only with the deviate, the latter interpretation can be ruled out. The second major difference between the present study and the studies by Schachter (1951) and Emerson (1954) is that in the present study the relationship between the $S$ and the other members of the group was divided into two components. If the $S$ is a member of the majority, there can exist a high or low degree of similarity between himself and the other members of the majority and a high or low degree of similarity between himself and the deviate. Either dimension could be the critical variable to the exclusion of the other. However, since both dimensions make up the total degree of intragroup similarity, it was predicted that both dimensions would be directly related to the speed with which the $S$ would reject the deviate. The greater similarity between the $S$ and the other members of the majority and the greater the similarity between the $S$ and the deviate, the sooner should the $S$ break off communication with a nonconforming deviate.

\section{METHOD}

At a preliminary session, 32 females from an introductory sociology/ anthropology course at the University of Victoria were asked to fill out a personality questionnaire (the Leary Interpersonal Adjective Checklist). The Ss were then asked to participate in a subsequent experiment involving group discussion and were informed that the questionnaire would be employed in selecting the group members.

Upon arriving for the second session, the $S$ was seated in a small cubicle facing a one-way mirror, told to read a one-page description of a juvenile delinquent by the name of Johnny Rocco, and asked whether it would be better to send this person to prison or to a home for emotionally disturbed children. The $S$ was then asked to try to convince a "hypothetical other person" that the alternative she (the $S$ ) had picked was the best alternative. The $S$ talked over an intercom for $30 \mathrm{sec}$, rested for $30 \mathrm{sec}$, talked for $30 \mathrm{sec}$, etc., until she indicated that she had nothing further to say. The number of $30-\mathrm{sec}$ intervals employed by the $S$ was used to establish her operant rate.

The $S$ was then told that she was "Subject E" and (erroneously) that there were four other girls participating in the experiment: Ss A, B, C, and D. It was explained that each $S$ was located in a different room and that all rooms were connected via intercom. The $S$ was then given a card that indicated the relationship between her personality and the personalities of the other group members (information supposedly obtained from the personality questionnaire completed at the preliminary session). In one condition (high similarity to the majority, high similarity to the deviate), the card indicated that $S s \mathrm{~A}, \mathrm{~B}, \mathrm{C}, \mathrm{D}$, and $\mathrm{E}$ possessed a "Type I" personality and that no one possessed a "Type II" or "Type III" personality. In a second condition (high similarity to the majority, low similarity to the deviate), the card indicated that $S s A, B, C$, and $E$ possessed a "Type I" personality, that D possessed a "Type II" personality, and that no one possessed a "Type III" personality. In a third condition (low similarity to the majority, high similarity to the deviate), the card indicated that $S$ s $A, B$, and $C$ possessed a "Type I" personality, that D 
Table 1

Mean Number of 30-Sec Communication Intervals Employed Before Cessation of Communication

\begin{tabular}{lllcrr}
$\begin{array}{l}\text { Similarity } \\
\text { to Deviate }\end{array}$ & $\begin{array}{c}\text { Similarity } \\
\text { to Majority }\end{array}$ & $\mathrm{n}$ & Operant & Experimental & Change \\
& Low & 8 & 3.50 & 5.38 & 1.88 \\
Low & High & 8 & 4.88 & 5.25 & .37 \\
& Low & 8 & 3.88 & 4.13 & .25 \\
High & High & 8 & 5.00 & 3.89 & -1.11 \\
\hline
\end{tabular}

and E possessed a "Type II" personality, and that no one possessed a "Type III" personality. And in the fourth condition (low similarity to the majority, low similarity to the deviate), the card indicated that $\mathrm{Ss} \mathrm{A}, \mathrm{B}$, and $\mathrm{C}$ possessed a "Type I" personality, that E possessed a "Type II" personality, and that D possessed a "Type III" personality. The S was then informed that Ss A, B, C, and E had chosen the same alternative after reading the Johnny Rocco case and that $D$ had chosen the other alternative. This established $A, B$, and $C$ (along with $E$, the $S)$ as members of the majority and $D$ as the deviate.

After the $S$ had been given information regarding the personalities of the other group members and their opinions on the Johnny Rocco case, she was told that the group would discuss this case and should, as a group, come to a conclusion as to which of the two alternatives was the better way of dealing with this juvenile delinquent. The procedure for the first phase of the experiment was then explained. The $S$ would be allowed to communicate with $\mathrm{D}$ (although D would not be allowed to respond). The $S$ would talk for $30 \mathrm{sec}$, rest for $30 \mathrm{sec}$, talk for $30 \mathrm{sec}$, etc., until she indicated that she had nothing further to say to $D$.

After the procedure had been explained, the $E$ retired to an adjoining room (connected with the S's room via intercom) and instructed the $S$ to talk over the between themselves and the deviate than when there was a low similarity $(F=4.39$, $\mathrm{df}=1 / 27, \mathrm{p}<.05)$. It was initially predicted that $\mathrm{Ss}$ would break off communication with the deviate sooner when there was a high perceived similarity between themselves and the other members of the majority than when there was a low similarity. Although the means were in the appropriate direction, this difference was not significant $(\mathrm{F}=2.25, \quad \mathrm{df}=1 / 27$, $p>.05)$. The effect of this variable might have been stronger had there been more contact between the $S$ and the other members of the majority. The interaction between the two dimensions of similarity was not significant $(\mathrm{F}<1)$. The means are presented in Table 1.

As expected, Ss broke off communication with the deviate sooner when both dimensions of similarity were high than when bath dimensions were low $(t=4.30 ; d f=14 ; p<.01) .^{2}$ This finding would seem to extend the generality of the results obtained by Schachter (1951) and Emerson (1954). It is interesting to note, however, that the relationship between the $S$ and one member of the group (the deviate) was just as important (if not more important) than the relationship between the $S$ and all remaining members of the group put together! there is a low similarity. There appeared to be some initial difference among the four groups in terms of their communication scores during the operant period. To control for these differences, a two-way analysis of covariance was carried out on the data. The number of 30 -sec intervals employed to communicate with the deviate served as the criterion variable, and the number of 30 -sec intervals employed to communicate with the "hypothetical other person" during the operant period served as the covariate. As expected, Ss broke off communication with the deviate sooner when there was a high perceived similarity
REFERENCES

EMERSON, R. M. Deviation and rejection: An experimental replication. American Sociological Review, 1954, 19,688-694.

FESTINGER, L. Informal social communication. Psychological Review, 1950, 57, 271-282.

SCHACHTER, S. Deviation, rejection, and communication. Joumal of Abnormal \& Social Psychology, 1951, 46, 190-207. NOTES

1. This report is based on a Senior Honors thesis carried out by the junior author under the direction of the senior author.

2 . In this analysis, a $t$ test was carried out on the change scores. 